7. Reprod. Fert. (1966) 11, 325-331

\title{
EFFECT OF OESTRADIOL-17 $\beta$ ON FERTILIZED RABBIT EGGS IN VITRO
}

\author{
ROBERT W. MaGAUGHEY AND JOSEPH G. DANIEL, JR. \\ Department of Biology, University of Colorado, Boulder, Colorado
}

(Received 23rd Fune 1965, revised 7th November 1965)

Summary. The effect of oestradiol- $17 \beta$ on fertilized rabbit eggs in vitro was studied following its inclusion in the culture medium.

When oestradiol is present at a concentration of $25 \mu \mathrm{g} / \mathrm{ml}$ and several hours remain between the time of exposure and the expected time of first cleavage, single-celled eggs typically fail to cleave and amphimixis appears to be inhibited. If the concentration of oestradiol is reduced to $10 \mu \mathrm{g} / \mathrm{ml}$, or if the first cleavage is imminent at the time of exposure, the eggs tend to fragment instead of undergoing normal cleavage, presumably an effect on the cell membrane. Most eggs are apparently unaffected by an oestradiol concentration of $5 \mu \mathrm{g} / \mathrm{ml}$. A minimal exposure time of about $30 \mathrm{~min}$ is necessary to achieve an oestradiol response. Two- and fourcelled stages are much more resistant to the oestrogen than are singlecelled ones.

The degree of fragmentation is reduced when progesterone is added equimolarly with oestradiol, suggesting that some antagonistic interaction occurs.

Under incubator conditions the concentration of oestradiol remains constant throughout the time of these experiments but that of oestrone appears to decrease.

\section{INTRODUCTION}

It has been observed by an increasing number of investigators that certain steroid sex hormones have injurious effects on the development of early mammalian embryos both in vivo and in vitro. Tube locking of rabbit eggs was observed by Burdick \& Pincus (1935) after injecting low concentrations of oestrone into recently mated does. The development of rabbit blastocysts was found to be interrupted by daily injections of 900 rat units of oestrone (Pincus \& Kirsch, 1936). Interruption of pregnancy has been observed in rabbits injected with various concentrations of oestradiol-17 $\beta$ and oestradiol benzoate (e.g. Greenwald, 1957, 1959, 1961, 1963; Adams, Hay \& Lutwak-Mann, 1961; Schofield, 1962). The details of progesterone effects in vitro on mouse eggs (Whitten, 1957) and on rabbit eggs (Daniel \& Levy, 1964) have been discussed.

A preliminary investigation of the effects of certain steroids on rabbit eggs (Daniel, 1964) revealed that oestrone, oestriol and oestradiol-17 $\beta$ act similarly to interrupt cleavage of rabbit eggs by fragmentation. In the present study oestradiol-17 $\beta$ was used in an attempt to clarify the nature of this effect. 


\section{MATERIALS AND METHODS}

A total of thirty-four random-bred domestic rabbits was used in this study. They were all ovulated naturally by mating with two bucks. Eggs in the singlecell stage were flushed from the oviducts between 19 and $23 \mathrm{hr}$ after mating and collected in large, sterile watch-glasses (Daniel \& Levy, 1964). The eggs were transferred, via capillary pipettes, into small, disposable, organ-culture dishes (three to four eggs/dish) containing $1 \mathrm{ml}$ of the test media.

The culture medium (F10R15) employed in this study was composed of 85 parts $\mathrm{F} 10$ (Ham, 1963) and 15 parts maternal rabbit serum. Oestradiol-17 $\beta$ was added in various concentrations to this medium. A stock solution of the steroid was made up in a concentration of $2500 \mu \mathrm{g} / \mathrm{ml}$ in $95 \%$ ethanol. A $100-$ fold dilution of this stock solution with F10R15 resulted in a $25 \mu \mathrm{g} / \mathrm{ml}$ test medium which had an alcohol content of less than $1 \%$. This alcohol concentration is not injurious to rabbit eggs (Daniel \& Levy, 1964). Concentrations of 5 and $10 \mu \mathrm{g}$ of oestradiol- $17 \beta / \mathrm{ml}$ of $\mathrm{F} 10 \mathrm{R} 15$ were also used.

Control eggs were retained in steroid-free medium, as tests of the medium and of egg viability. The dishes containing eggs and media were incubated at $37.5^{\circ} \mathrm{C}$, in an atmosphere composed of $5 \% \mathrm{CO}_{2}$ in air. Results were read within $3 \mathrm{hr}$ after the controls had cleaved and again $24 \mathrm{hr}$ later.

Three different series of culture experiments were performed on single-cell eggs and repeated in part on two- and four-cell stages. The first was an attempt to correlate the effects of steroid concentration with age of the eggs (in relation to anticipated time of cleavage). In these studies, eggs removed at 19 to 20 , 21 and 22 to $23 \mathrm{hr}$ after mating were exposed to one of the three test concentrations described above. Since the first cleavage may occur as early as 22 to $23 \mathrm{hr}$ after mating (Lewis \& Gregory, 1929), then these ages represent times of 3 to 4, 1 to 2 and 0 to $1 \mathrm{hr}$ before the expected time of cleavage.

In a second group of experiments, single-cell eggs (19 to $21 \mathrm{hr}$ after mating) were exposed to $25 \mu \mathrm{g} / \mathrm{ml}$ of oestradiol for varying lengths of time, after which the eggs were transferred to steroid-free control medium. The shortest duration of exposure was $15 \mathrm{~min}$, the longest was $90 \mathrm{~min}$.

The purpose of the third set of experiments was to determine any possible interaction between oestradiol and progesterone. In these experiments two different equimolar test solutions were employed: one containing $0.037 \mathrm{~mm}$ of oestradiol-17 $\beta(10 \mu \mathrm{g} / \mathrm{ml})$ and progesterone $(12.5 \mu \mathrm{g} / \mathrm{ml})$, and the other containing $0.074 \mathrm{~mm}$ of these two hormones. Eggs used were in the age range of 19 to $20 \mathrm{hr}$ after mating.

In all of the studies described above, ten to fifteen eggs were used in each concentration of the oestrogen, the controls and at each time period. A total of 207 eggs was used.

In order to determine the condition of the nucleus, a number of steroidtreated eggs were serially sectioned and stained with haematoxylin and eosin.

Since these studies involved prolonged exposure of an oestrogen to incubator temperature, a series of experiments was carried out to establish possible decomposition rates for oestrone and oestradiol- $17 \beta$, solutions of which were made up in a concentration of $0.15 \mathrm{~mm}$, using $95 \%$ ethanol as the solvent. 
These solutions were incubated at $37.5^{\circ} \mathrm{C}$ after reference samples had been analysed spectrophotometrically (Beckman D.B. Spectrophotometer at $280 \mathrm{~m} \mu$ ). A series of incubated samples was sequentially analysed over a $16-\mathrm{hr}$ period.

\section{RESULTS}

During normal development in vivo, fertilized rabbit eggs undergo their first cleavage at 22 to $25 \mathrm{hr}$ after mating, or approximately 11 to $13 \mathrm{hr}$ after sperm penetration. The same rates of development have been observed when eggs are removed from the female at 17 to $18 \mathrm{hr}$ after mating, and incubated at $37.5^{\circ} \mathrm{C}$ in F10R 10 culture medium (Daniel, 1964).

In all of the initial experiments, where eggs of different ages were kept in media containing different concentrations of oestradiol, $100 \%$ of the controls cleaved normally to the two-cell stage within the expected first cleavage period.
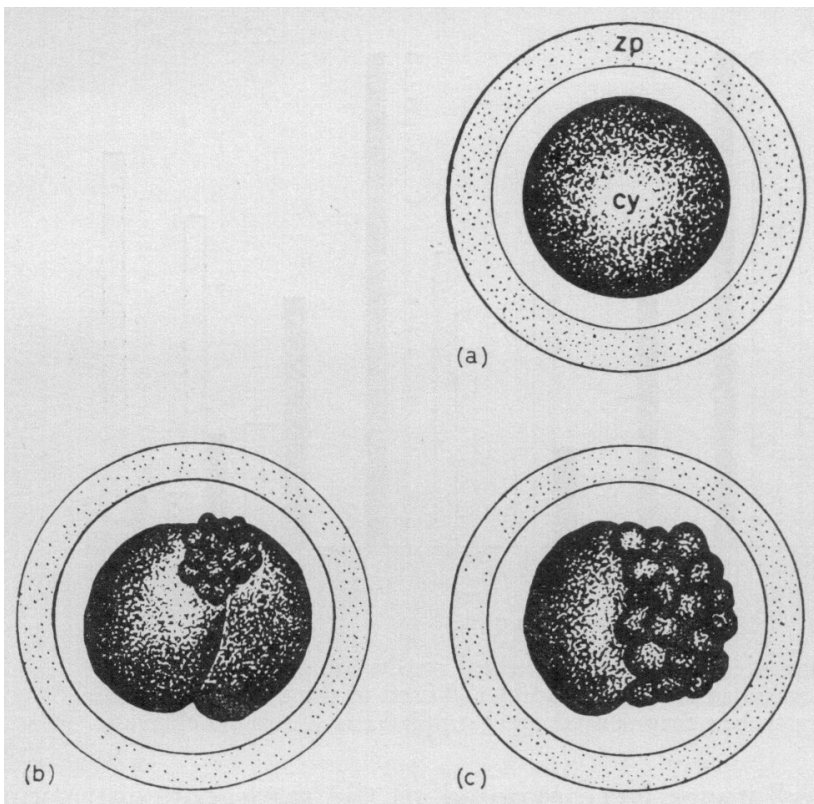

TEXT-FIG. 1. Diagrammatic representations of various responses of rabbit eggs to oestradiol. (a) An inhibited egg (cy, egg cytoplasm; zp, zona pellucida). (b to d) Degrees of fragmentation.

The steroid-treated eggs exhibited one of three different conditions: normal cleavage, inhibition or fragmentation. The inhibition effect consisted of blockage of cleavage so that the eggs remained at the single-cell stage when, according to their age, they would be expected to be two or more cells. Others of the steroid-treated eggs appeared to develop into a large number of small fragments (Plate 1). This fragmentation was found, in other studies, to take place at the approximate time at which normal cleavage is expected (Daniel, 1964). Fragmentation is not a completely predictable phenomenon, since different degrees of it occurred (see Text-fig. 1). Some fragmentations occurred only around the cleavage furrow instead of around the entire surface of the egg, 
and in other cases one or more large 'cells' (blastomeres?) were present in addition to a number of small fragments.

The data recorded for these experiments are shown graphically in Text-fig. 2 . It is apparent from this graph that the highest frequency of inhibition occurred in 19- to $20-\mathrm{hr}$ eggs which were treated with $25 \mu \mathrm{g} / \mathrm{ml}$ oestradiol. At this concentration the relative proportion of inhibited eggs decreases with age, while fragmentation increases. It is also evident from Text-fig. 2 that the percentage of inhibition decreases with age and that the incidence of fragmentation stays relatively constant in eggs which were treated with the intermediate concentration (i.e. $10 \mu \mathrm{g} / \mathrm{ml}$ ). The $5 \mu \mathrm{g} / \mathrm{ml}$ concentration had some effect on the older eggs but none on the 19- to $20-\mathrm{hr}$ group. Taken collectively, less inhibition accompanied by more fragmentation was observed in 22- to 23-hr eggs, than for the other age-ranges.

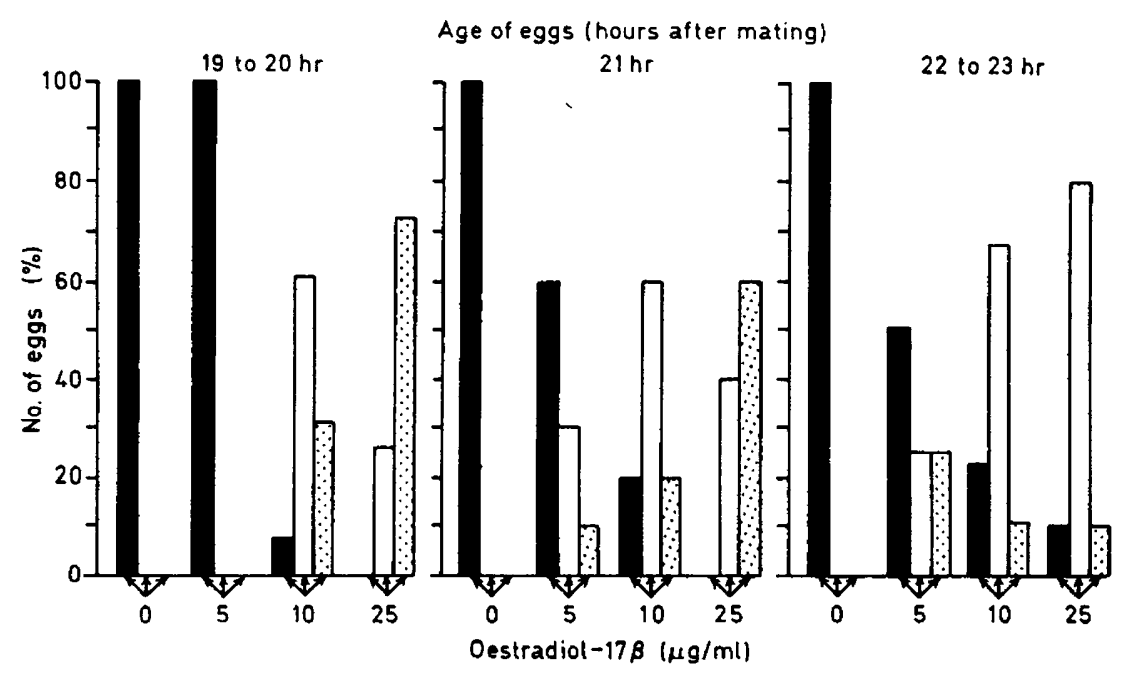

TEXT-FIG. 2. Graphic representation of the experimental results for studies comparing the age of the ova with the concentration of oestradiol-17 $\beta$ used in the culture medium. Solid bar, Normal cleavage; open bar, fragmented eggs; stippled bar, inhibited cleavage.

When two- and four-celled stages were exposed to the same concentration of oestradiol as noted for the single-cell stage, similar results were observed. However, in no case did the $5 \mu \mathrm{g} / \mathrm{ml}$ concentration have any effect on continued normal cleavage, whereas $85 \%$ of the eggs of these ages were inhibited by $25 \mu \mathrm{g} / \mathrm{ml}$. At the $10 \mu \mathrm{g} / \mathrm{ml}$ concentration $20 \%$ of the two-celled eggs and $25 \%$ of those at the four-celled stage were inhibited or fragmented. Obviously the concentration of oestradiol needed to have any observable effect on multicellular embryos must be higher than the minimum that affects the unicellular stage.

The experiments involving varied exposure periods demonstrated that singlecelled rabbit eggs must be in the presence of oestradiol-17 $\beta$ (in a concentration of $25 \mu \mathrm{g} / \mathrm{ml}$ ) for $30 \mathrm{~min}$ for the steroid to be effective. Shorter exposure is inadequate for the induction of a typical oestrogenic effect. Fragmentation was the only effect observed in this series of experiments. 
PLATE 1

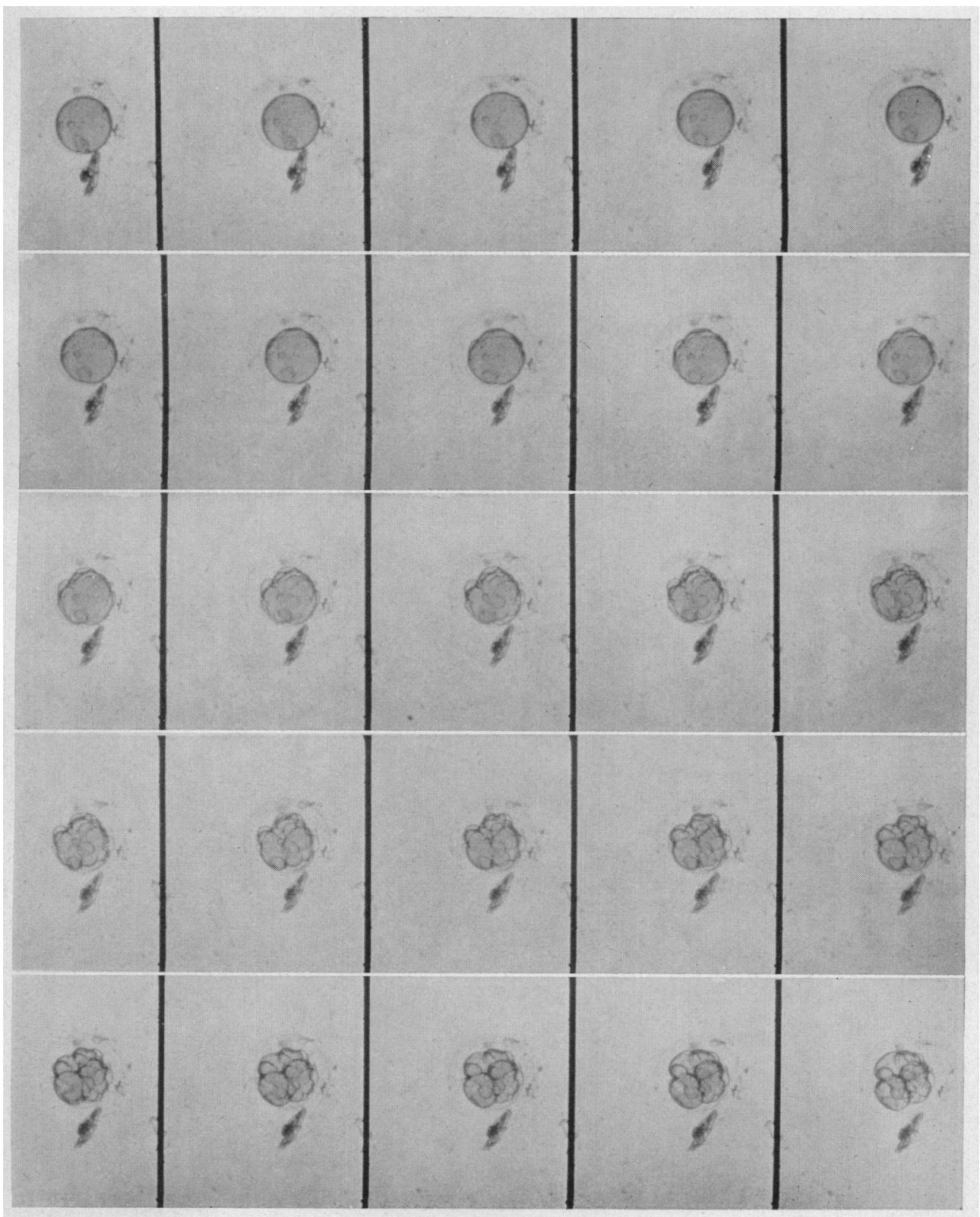

Sequence of frames of a time-lapse cinematograph showing a rabbit egg undergoing fragmentation. Exposures are separated by $1 \mathrm{~min} . \times 50$ diameters.

(Facing p. 328) 
PLATE 2

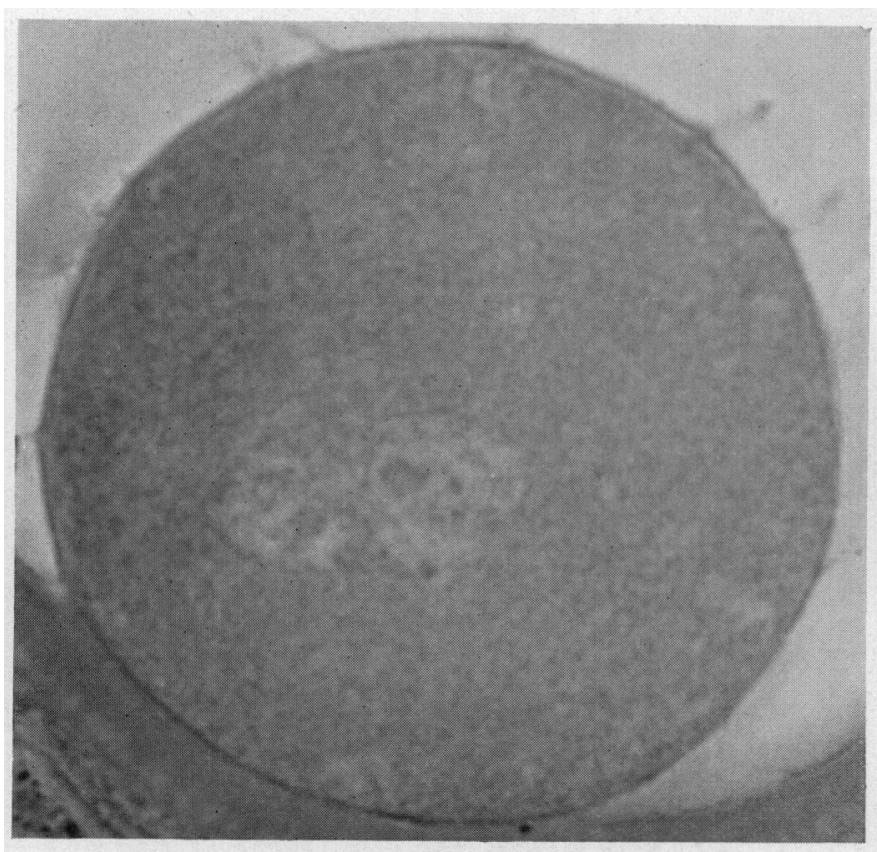

Section of a rabbit egg in which cleavage has been inhibited by ocstradiol, showing two pronuclei. $\times 500$ diancters. 
Of the twenty-two eggs exposed to equimolar concentrations of oestradiol and progesterone, sixteen were fragmented and two inhibited. However, the fragmentation in all of these cases was very slight, being mainly localized around the cleavage furrow and resembling the condition shown in Text-fig. 1(b). Some antagonistic effect is, therefore, indicated.

Sections of single-celled eggs (Plate 2) that have been inhibited show that fusion of the pronuclei has not yet been completed although the nuclear membranes are relatively indistinct.

In the spectrophotometric studies the concentration of oestrone changed with time at incubation temperature as determined by measurement of u.v. transmission, while oestradiol showed no significant change (see Text-fig. 3).

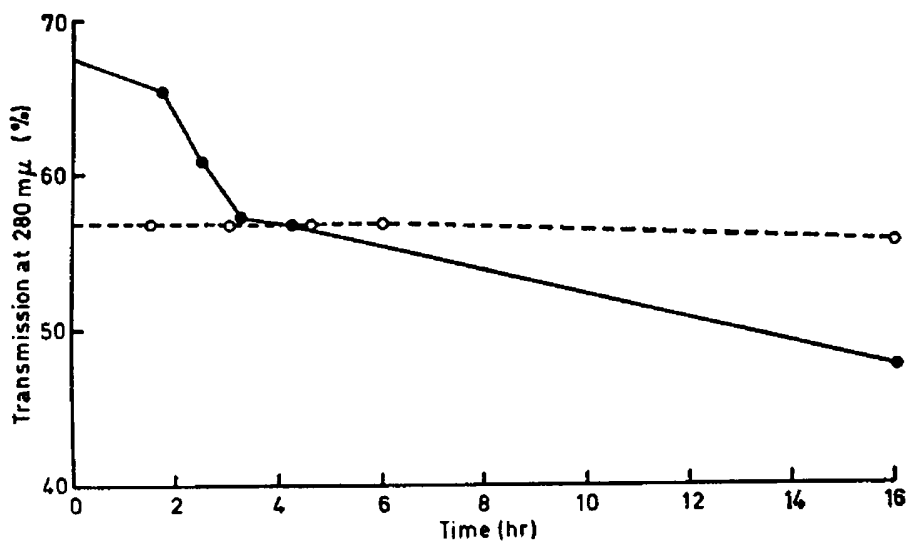

TEXT-FIG. 3. Oestrogen concentration as determined spectrophotometrically after exposure to incubator temperatures. $Q$, Oestrone; $O$, oestradiol-17 $\beta$.

\section{DISCUSSION}

In the experiments carried out well in advance of the first cleavage, the proportion of eggs showing inhibition of cleavage increases with steroid concentration. When cleavage is imminent and, therefore, reaction time limited, the proportion of fragmented eggs increases with steroid concentration. Of the eggs exposed for limited periods to oestradiol and then removed to steroidfree medium, only fragmentation was observed. Therefore it appears that the fragmentation phenomenon is an intermediate effect between normal cleavage and inhibition. That less inhibition occurred as the age of eggs increased toward the time of the first cleavage, supplies evidence for the idea of steroid-blockage of some metabolic event necessary for normal cleavage.

The exact mechanisms by which fragmentation or inhibition occur are not yet clear, although fragmentation is obviously detectable as an effect on the cell membrane. Willmer (1961) attempted to correlate the structure of membrane surfaces and the structural configuration of steroid molecules with the reported steroid-to-cell activities. He has postulated that the fourth-ring $\mathrm{OH}$ group of oestrogens, and the fourth-ring end-group of progesterone penetrate the cell membrane between the phospholipid-aliphatic groups, and thereby 
leave the first-ring groups exposed. This hypothesis suggests quite logically the manner in which steroids may become attached to cell membranes and thereby potentially change the permeability and polarity of the membranes.

The question of steroid affinity for the cell surface was approached through experiments in which the oestradiol exposure-period was varied. It appears, from these studies, that there is a minimum amount of time needed for steroidcell interaction. Since no inhibition of cleavage was observed in these eggs, it was suggested that a sufficient amount of oestrogen had been removed from the eggs by the steroid-free wash solution, so that only fragmentation or normal cleavage resulted.

A cell-surface reaction does not exclude the possibility of other intra-cellular reactions of steroids on cells (e.g. Mueller, 1957; Jervell, Diniz \& Mueller, 1958; Gorski \& Nicolette, 1963; Davidson, 1965). Daniel (1964) reported that no intact nuclei were found in fragmented rabbit eggs observed by means of the acetic-orcein, squash technique. In the present study, stained, serial sections of fragmented rabbit eggs were prepared to determine the nuclear condition of these abnormal embryos. No nuclei were observed in any surface fragments, although, in some eggs which were only slightly fragmented, intact nuclei were found in the blastomeres. Some inhibited eggs were found to have two nuclear bodies (Plate 2) that are believed to be pronuclei that had not yet undergone amphimixis. Thus it appears that other effects on the nuclei or pronuclei exist which may be independent of the surface phenomenon or may be secondarily initiated because of cell membrane modifications. Sea-urchin eggs become irregularly segmented by exposure to low oestradiol concentrations, and with higher concentrations, cleavage is inhibited (Agrell, 1954) but the nuclei of the inhibited eggs continue to divide, forming a syncytium. Apparently the steroid effect on these invertebrate embryos does not involve the nucleus.

The observation that two- and four-celled stages respond somewhat differently to the oestrogen than does the single cell stage suggests possible differences in sensitivity or in mechanism of action. The increased cell surface area of multicellular stages might account for the failure of low concentrations of oestradiol to have any effect, or the absence of pronuclei in these later stages may eliminate the possibility of some influence that is unique to that nuclear condition.

Text-fig. 2 shows that eggs exposed to the $5 \mu \mathrm{g} / \mathrm{ml}$ concentration for 3 to $4 \mathrm{hr}$ before expected cleavage all cleaved normally, whereas those exposed for shorter periods were sometimes inhibited or fragmented. These results gave rise to the suspicion that the steroid might be partially de-activated after several hours at incubator temperature: an effect that could be the product of decomposition or of binding of the oestrogen molecules with the soluble proteins or amino acids of the culture medium. It was impossible to demonstrate oestradiol$17 \beta$ in the culture medium spectrophotometrically so an ethanolic solution was used. These studies showed that oestradiol-17 $\beta$ did not decompose significantly (in alcohol) when exposed to incubator temperatures for a prolonged period, although under the same conditions the concentration of another oestrogen, oestrone, is changed. This observation does not, however, preclude the possibility of binding and/or degradation of oestradiol under the experimental conditions employed in this study. 
At present it is difficult to correlate the results obtained from experiments involving steroid effects on mammalian embryos in vivo and in vitro. The reports of pregnancy interruption and of oestrogen-induced infertility in vivo may be related, in part, to the action of oestrogens on developing embryos. Recent attempts to grow rabbit eggs in vivo after treatment with very high concentrations of oestradiol in vitro showed that short exposure had no detectable effect, but prolonged exposure was lethal (Ketchel \& Pincus, 1964). High concentrations of oestrogenic hormones injected into pregnant females typically cause either tube-locking, as noted earlier, or expulsion of the eggs due possibly to muscular activity in the uterus and/or oviduct (Greenwald, 1957, 1959; Schofield, 1962). Thus, eggs are lost from the genital tract before a direct effect can be determined. The question, therefore, of whether oestrogeninduced fragmentation or inhibition of the fertilized egg, as observed in vitro, could also occur in vivo will be difficult to resolve.

\section{ACKNOWLEDGMENT}

\section{This research was supported by N.S.F. Grant GB-44.}

\section{REFERENCES}

Adams, C. E., Hay, M. G. \& LuTwak-Mann, C. (1961) The action of various agents upon the rabbit embryo. F. Embryol. exp. Morph. 9, 468.

Agrell, I. (1954) Oestradiol and testosterone proprionate as mitotic inhibitors during embryogenesis. Nature, Lond. 173, 172.

Burdick, A. O. \& Pincus, G. (1935) The effect of oestrone injections on the developing ova of mice and rabbits. Am. F. Physiol. 111, 201.

Daniel, J. C. (1964) Some effects of steroids on cleavage of rabbit eggs in vitro. Endocrinology, 75, 706.

DANIEL, J. C. \& LEVY, J. D. (1964) Action of progesterone as a cleavage inhibitor of rabbit ova in vitro 7. Reprod. Fert. 7, 323.

DAvidson, E. H. (1965) Hormones and genes. Scient. Am. 212, 36.

Gorski, J. \& NrcoletTE, J. (1963) Early estrogen effects on newly synthesized RNA and phospholipid in subcellular fractions of rat uterus. Archs Biochem. Biophys. 130, 418.

Greenwald, G. S. (1957) Interruption of pregnancy in the rabbit by administration of estrogen. 7. exp. Zool. $135,461$.

GreEnwald, G. S. (1959) The comparative effectiveness of estrogens in interrupting pregnancy in the rabbit. Fert. Steril. 10, 155.

GreENWALD, G. S. (1961) The antifertility effect in pregnant rats of a single injection of estradiol cyclopentylproprionate. Endocrinology, 69, 1068.

GREENWALD, G. S. (1963) Interruption of early pregnancy in the rabbit by a single injection of oestradiol cyclopentylproprionate. F. Endocr. 26, 133.

Ham, R. G. (1963) An improved nutrient solution for diploid Chinese hamster and human cell lines. Exp. Cell Res. 29, 515.

Jervell, K. F., Diniz, C. R. \& Mueller, G. C. (1958) Early effects of estradiol on nucleic acid metabolism in the rat uterus. 7 . biol. Chem. 231, 945.

Ketchel, M. M. \& Pincus, G. (1964) In vitro exposure of rabbit ova to estrogens. Proc. Soc. exp. Biol. Med. 115, 419.

Lewis, W. H. \& Gregory, P. W. (1929) Cinematographs of living developing rabbit eggs. Science, N.r. 69, 226.

MuELLER, G. C. (1957) A discussion of the mechanism of action of steroid hormones. Cancer Res. 17, 490.

Pincus, G. \& Kirsch, R. E. (1936) The sterility in rabbits produced by the injection of oestrone and related compounds. Am. F. Physiol. 115, 219.

Schofield, B. M. (1962) The effect of injected oestrogen on pregnancy in the rabbit. F. Endocr. 25, 95.

WhitTEN, W. K. (1957) The effect of progesterone on the development of mouse eggs in vitro. F. Endocr. $16,80$.

WiLLmer, E. N. (1961) Steroids and cell surfaces. Biol. Rev. 36, 368. 